\title{
Regional Aggregation in Forecasting: An Application to the Federal Reserve's Eighth District
}

\author{
Kristie M. Engemann, Rubén Hernández-Murillo, and Michael T. Owyang
}

\begin{abstract}
Hernández-Murillo and Owyang (2006) showed that accounting for spatial correlations in regional data can improve forecasts of national employment. This paper considers whether the predictive advantage of disaggregate models remains when forecasting subnational data. The authors conduct horse races among several forecasting models in which the objective is to forecast regional- or state-level employment. For some models, the objective is to forecast using the sum of further disaggregated employment (i.e., forecasts of metropolitan statistical area [MSA]-level data are summed to yield state-level forecasts). The authors find that the spatial relationships between states have sufficient predictive content to overcome small increases in the number of estimated parameters when forecasting regional-level data; this is not always true when forecasting stateand regional-level data using the sum of MSA-level forecasts. (JEL C31, C53)
\end{abstract}

Federal Reserve Bank of St. Louis Review, May/June 2011, 93(3), pp. 207-22.

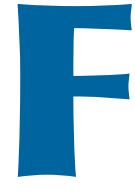

orecasting, especially as it pertains to policymaking, is typically conducted at the national level. ${ }^{1}$ However, a few recent papers have indicated that aggregating regional forecasts may improve forecasts of national indicators. For example, Hendry and Hubrich (2006) use disaggregate models to form forecasts for aggregate variables. Similarly, Giacomini and Granger (2004) show that using a disaggregate model that accounts for spatial

\footnotetext{
1 There are, however, some notable exceptions of forecasting economic indicators at the subnational level (dates and regions noted in parentheses): Glickman (1971, Philadelphia MSA); Ballard and Glickman (1977, Delaware Valley); Crow (1973, Northeast Corridor); Baird (1983, Ohio); Liu and Stocks (1983, Youngstown-Warren MSA); Duobinis (1981, Chicago MSA); LeSage and Magura (1986, 1990, Ohio); and Rapach and Strauss (2005, Missouri; 2007, Eighth Federal Reserve District).
}

correlations can reduce the root mean squared error of the forecasts. Their disaggregate forecasts take advantage of cross-regional correlations yet still restrict the number of parameters estimated. ${ }^{2}$ They argue that, under certain conditions, the sum of the forecasts from an order- $p, q$ spacetime autoregression [ST-AR $(p, q)]$ can outperform both aggregate models and models that do not account for the spatial nature of the data. The $\operatorname{ST}-\operatorname{AR}(p, q)$ model includes $p$ temporal lags and $q$ spatially distributed lags-that is, lags of the other regional series weighted by proximity. Thus, the $\operatorname{ST}-\operatorname{AR}(p, q)$ model exploits both the

2 Compared with a standard vector autogression (VAR), the spacetime autoregression (AR) model posited in Giacomini and Granger (2004) requires the estimation of $\left(n^{2}-n-1\right) p$ fewer parameters for the same lag order $p$.

Kristie M. Engemann is a former senior research associate, Rubén Hernández-Murillo is a senior economist, and Michael T. Owyang is a research officer at the Federal Reserve Bank of St. Louis. This paper was prepared for the 4th Annual Business and Economics Research Group conference sponsored by the Federal Reserve Bank of St. Louis and the Center for Regional Economics—8th District on March 28, 2008, in Columbia, Missouri (as part of the Missouri Economics Conference). It appeared in Federal Reserve Bank of St. Louis Regional Economic Development, October 2008, 4(1), pp. 15-29. The authors thank Dave Rapach for comments.

(C) 2011, The Federal Reserve Bank of St. Louis. The views expressed in this article are those of the author(s) and do not necessarily reflect the views of the Federal Reserve System, the Board of Governors, or the regional Federal Reserve Banks. Articles may be reprinted, reproduced, published, distributed, displayed, and transmitted in their entirety if copyright notice, author name(s), and full citation are included. Abstracts, synopses, and other derivative works may be made only with prior written permission of the Federal Reserve Bank of St. Louis. 
spatial correlations and the information content in the disaggregated series.

Hernández-Murillo and Owyang (2006) take this approach to national employment data, showing that out-of-sample forecasts can be improved by modeling the spatial interactions between Bureau of Economic Analysis regions. They compare a $\operatorname{ST}-\operatorname{AR}(p, q)$ model with vector autoregressions (VARs) with various levels of disaggregation. They concluded that, as predicted by Giacomini and Granger (2004), information in regional employment data is useful for forecasting national employment.

In this paper, we are interested in whether the information content of regional data can be observed at a more disaggregated level. In particular, we ask whether information for states helps forecast regional data and whether information from cities helps forecast state data. To this end, we construct horse races among four competing models with different levels of disaggregation. We then conduct out-of-sample tests to determine which model produces the best short- and longhorizon forecasts. The data used in these experiments are state- and metropolitan statistical area (MSA)-level payroll employment. In each experiment, the disaggregate data are summed to yield either state- or regional-level aggregates. In each case, we ask whether models using the disaggregate data provide lower mean squared prediction errors (MSPEs) than the aggregate alternatives. We find that the spatial relationships among states have sufficient predictive content to overcome small increases in the number of estimated parameters. The same is not always true when forecasting state- and regional-level variables using the sum of MSA-level forecasts.

The next section reviews the four models used in the horse races, followed by a section that discusses the subnational data and the construction of the "aggregate" data. The results of the out-ofsample experiments are then presented, followed by the conclusion.

\section{MODELS}

The goal of this experiment is to produce an $h$-period-ahead forecast of an aggregate time series-for example, employment. In this context, "aggregate" does not necessarily mean "national," although it is an obvious interpretation. Instead, here aggregate time series are data that are the sum or weighted sum of a number of (forecastable) disaggregate series. These series can be disaggregated in any manner (e.g., by regions or industries). The aggregate forecast then can be constructed directly from aggregate data or from the sum (or weighted sum) of its components. We examine four alternatives.

Suppose that period- $t$ aggregate employment is denoted $Y_{t}$ and can be written as the sum of its $N$ disaggregate counterparts (henceforth referred to as "regions," which depending on the application may refer to either states or metro areas), $y_{n t}$, without error. ${ }^{3}$ Let $\hat{Y}_{t+h}$ be the $h$-period-ahead forecast of $Y$. A forecast from the simplest model, a univariate aggregate order- $p$ autoregression $(\operatorname{AR}(p)$, Model 1), has the form

(1) $\hat{Y}_{t+h}=\sum_{j=1}^{p} \Phi_{j} Y_{t+h-j}$,

where $p$ is the number of lags and $\Phi_{j}$ are scalar coefficients. ${ }^{4}$

A similar univariate model can be constructed to forecast each of the individual componentsin particular, region $n$ 's $h$-period-ahead level of employment, $\hat{y}_{n, t+h} \cdot{ }^{5}$ The aggregate forecast is the sum of the $N$ regional forecasts (Model 2):

(2) $\hat{Y}_{t+h}=\sum_{n=1}^{N} \hat{y}_{n, t+h}^{u n i}=\sum_{n=1}^{N} \sum_{j=1}^{p} \phi_{n j} y_{n, t+h-j}$,

where $\hat{y}_{n, t+h}^{u n i}$ is region $n$ 's employment forecast from the univariate $\operatorname{AR}(p)$ model and $\phi_{n j}$ are scalar coefficients.

\footnotetext{
3 The implicit assumption made here is that the aggregate is exactly the sum of its component parts. That is,$$
Y_{t}=\sum_{n=1}^{N} y_{n t}
$$

holds identically. Of course, the validity of this assumption depends greatly on the choice of data.

4 Potential constants and time trends are suppressed in this section for notational convenience.

5 Henceforth, we refer to the disaggregate components as "regions," although they can, in principle, be of any type (e.g., industry, state, MSA).
} 
An alternative to Model (2) that accounts for the comovement between the regions is a VAR forecast (Model 3). The aggregate forecast obtained from such a model can be written as

(3) $\hat{Y}_{t+h}=\sum_{n=1}^{N} \hat{y}_{n, t+h}^{\mathrm{var}}=\sum_{n=1}^{N} \sum_{k=1}^{N} \sum_{j=1}^{p} \Gamma_{n k j} y_{k, t+h-j}$,

where $\hat{y}_{n, t+h}^{\mathrm{var}}$ is region n's employment forecast and $\Gamma_{n k j}$ is the (scalar) lag-j effect of region $k$ on region n's employment taken from the VAR coefficient matrices.

Finally, we consider a ST-AR $(p, q)$ model (Model 4), which accounts explicitly for the spatial correlations among regions by imposing a relationship that depends on the proximity to a region's neighbors. The spatial weights $w_{n k}$ are chosen a priori and are intended to reflect proximity between pairs of regions, for example, in terms of geographic characteristics such as contiguity or distance. Interaction between regions is governed by a weighting matrix $W=\left\{w_{n k}\right\}$ satisfying

$$
\begin{aligned}
& w_{n k} \geq 0, \quad w_{n n}=0, \text { and } \sum_{k \neq n} w_{n k}=1 \\
& \hat{Y}_{t+h}=\sum_{n=1}^{N} \hat{y}_{n, t+h}^{\text {star }} \\
& =\sum_{n=1}^{N}\left[\sum_{j=1}^{p} \phi_{j} y_{n, t+h-j}+\sum_{k=1}^{N} \sum_{l=1}^{q} \psi_{l} w_{n k} y_{k, t+h-l}\right],
\end{aligned}
$$$$
\text { (4) }
$$

where $\phi_{j}$ and $\psi_{l}$ are scalar autoregressive and scalar spatial lag coefficients, respectively. The weighting matrices used in the empirical applications are discussed below.

The primary differences among the four models involve a tension between modeling the (in-sample) cross-spatial correlations and parameter proliferation. Clearly, Models (1) and (2) are the most parsimonious models. However, these models neglect potentially predictive information in the comovement between the variables. On the other hand, the VAR depicted in Model (3) may overfit the in-sample data. Under parameter certainty, the VAR forecast in Model (3) weakly dominates the three alternative Models (1), (2), and (4). However, Giacomini and Granger (2004) show that forecasting from an estimated VAR (Model 3) is less efficient than forecasting from the ST-AR model (Model 4). ${ }^{6}$ Because the ST-AR model is a restricted form of the VAR, the error associated with parameter uncertainty decreases. Giancomini and Granger, however, are unable to determine whether the ST-AR model or the univariate model is more theoretically efficient (i.e., whether interaction between regions yields significant information for forecasting). In the following section, we investigate whether accounting for spatial interaction in regional employment data is sufficiently elucidative to warrant the use of disaggregate data in forecasting.

\section{EMPIRICAL DETAILS}

Hernández-Murillo and Owyang (2006) tested the forecasting efficacy of the spatially disaggregated model for national employment. Here, we consider further disaggregation by examining the model's ability to forecast state- and Federal Reserve District-level employment. We conduct three experiments. First, we forecast Eighth District employment using the sum of state-level employment. ${ }^{7}$ Second, we forecast District employment using the sum of Eighth District MSA-level employment. ${ }^{8}$ Finally, we forecast state-level employment for each of the seven District states using MSA-level employment.

\section{Data}

Although a number of aggregate business cycle indicators exist, relatively few series are available at the disaggregate level. Two series available at a state level with both a reasonable

6 Under certain conditions, the univariate aggregate model yields a lower mean squared error. For a discussion of these conditions, see Giacomini and Granger (2004).

7 The Federal Reserve's Eighth District contains portions of seven states: Missouri, Illinois, Tennessee, Arkansas, Kentucky, Indiana, and Mississippi. Only Arkansas lies entirely in the Eighth District. However, for purposes of this experiment, we make the simplifying assumption that the District consists of the entirety of all seven states.

8 In constructing District-level employment for this experiment and state-level employment for the next experiment, we use the sum of MSA-level employment. For the former, we include only MSAs located in the Eighth District, and for the latter, we include all MSAs in the states. Rural employment is omitted in each case. 


\section{Figure 1}

\section{Eighth District States' Payroll Employment by State}

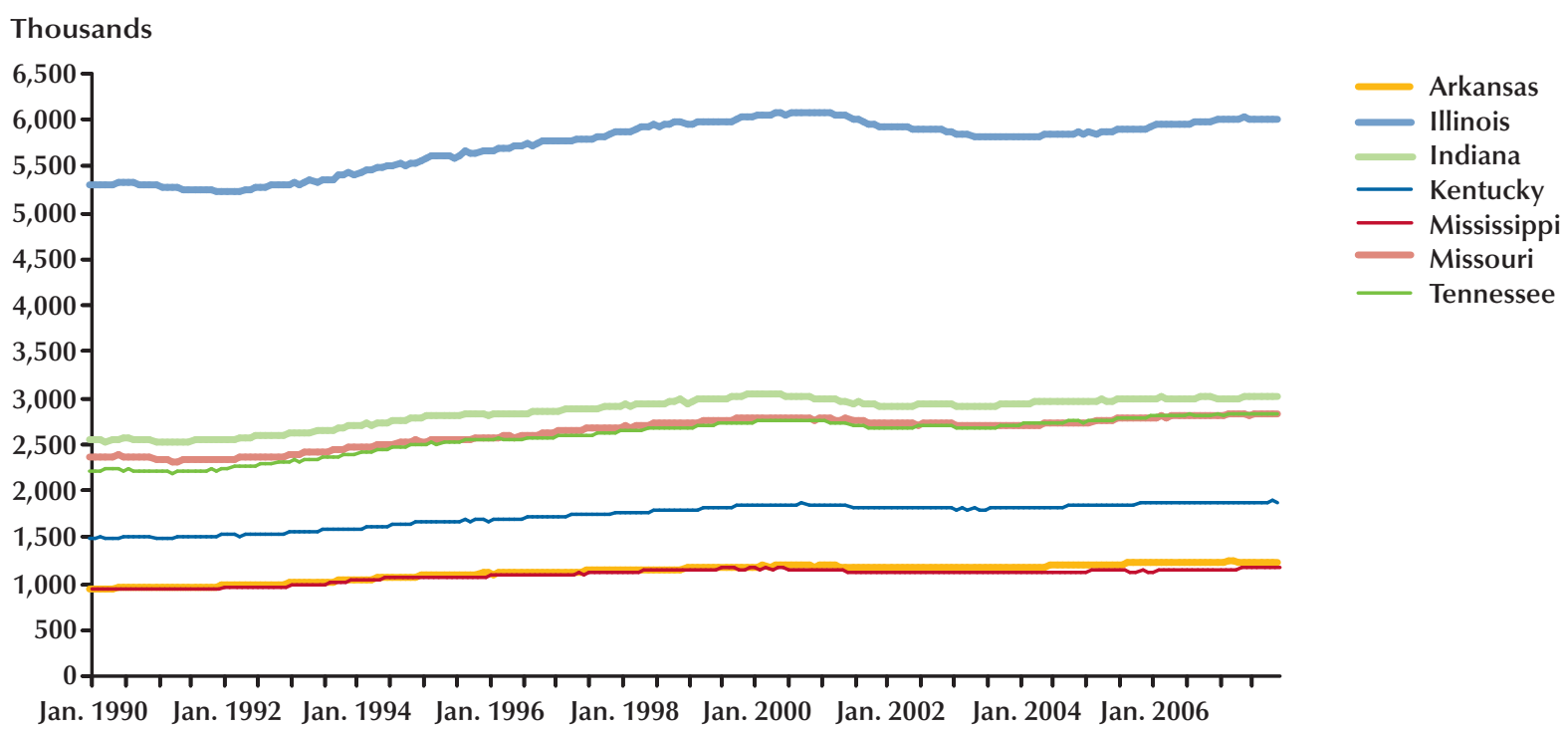

NOTE: The employment series for each state is seasonally adjusted.

frequency and sufficiently large sample are personal income (quarterly) and employment (monthly). ${ }^{9}$ At an MSA-level, only employment is readily available. We, therefore, concentrate our efforts on the appropriate employment forecasts.

For our forecasting experiments, we use stateand MSA-level employment data from the Bureau of Labor Statistics' payroll employment survey. For the first experiment, state-level employment is summed to yield an approximation of the Eighth District employment level. In the same manner, the appropriate aggregates are constructed from MSA-level data in the following two experiments for forecasting District- and state-level data. For each exercise, the full sample is January 1990 to December 2007. For convenience, the stateand MSA-level data are plotted in Figures 1 and 2, respectively. Summary statistics for the data are provided in Tables 1 and 2.

9 Gross state product, which is the state-level equivalent to national gross domestic product, is annual and only available at a one-year lag.
For each of the last two experiments, we construct the District- and state-level aggregates by omitting rural employment. Table 3 shows that the rural component of employment for each state in the Federal Reserve's Eighth District is significant. The difficulty, however, of adding rural employment to the forecasting regressions (at least those that account for cross-regional correlations) lies in modeling the comovements between rural and urban employment. In particular, for the spatial model (4), modeling the distance between the rural and MSA centroids is problematic.

\section{Forecasting Scheme}

We could use one of two forecasting schemesrecursive or rolling window. A recursive forecasting scheme fixes the initial period for the in-sample data. Each additional period is added to the sample and the model is reestimated. Thus, the estimation window expands as the sample expands. Conversely, the rolling window scheme fixes the size of the dataset used to make the fore- 


\section{Figure 2A}

\section{Eighth District MSAs' Payroll Employment by State}

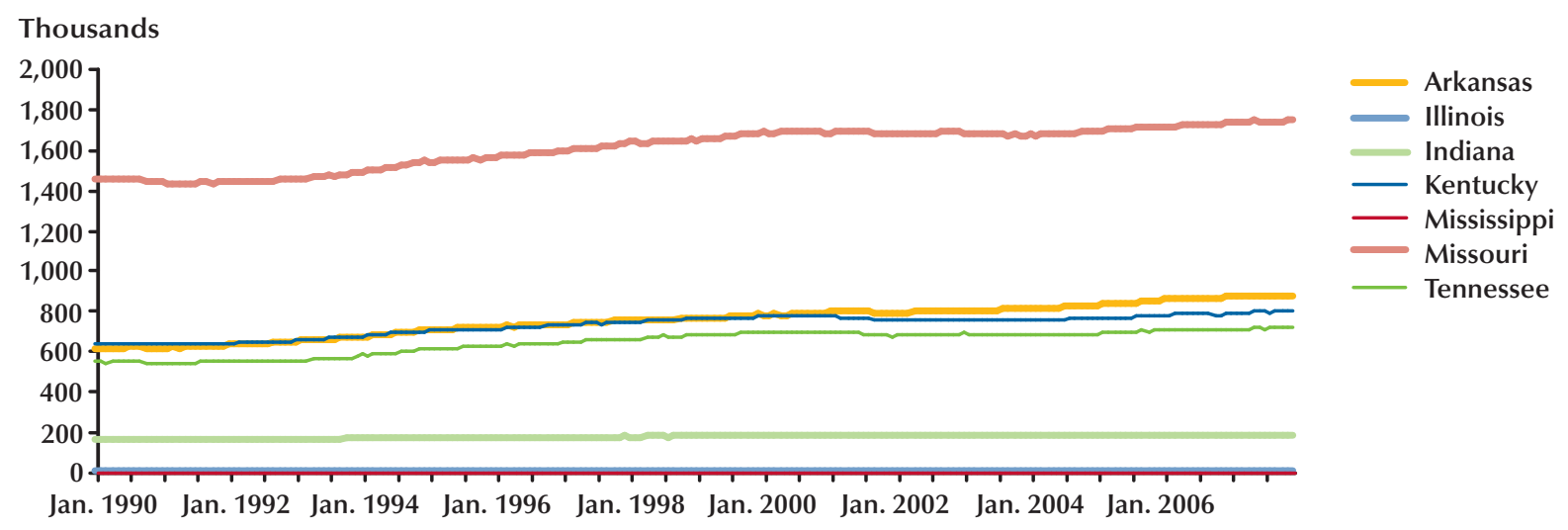

NOTE: The employment series for each state is seasonally adjusted and consists of the sum of all MSAs in that state.

\section{Figure 2B}

\section{Total State MSAs' Payroll Employment by State}

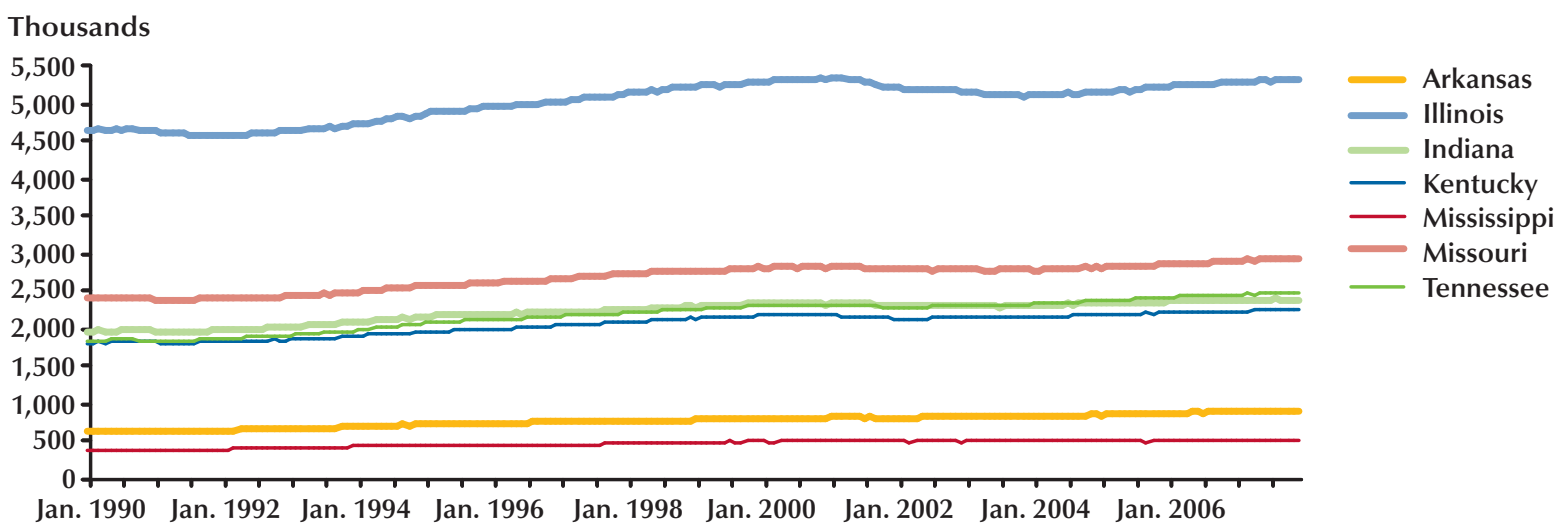

NOTE: The employment series for each state is seasonally adjusted and consists of the sum of all MSAs in that state. 


\section{Table 1}

\section{State-Level Summary Statistics}

\begin{tabular}{|c|c|c|c|c|c|c|c|c|c|c|c|c|c|}
\hline \multirow[b]{3}{*}{ State } & \multicolumn{7}{|c|}{ Level (thousands) } & \multicolumn{6}{|c|}{ Growth rate (percent) } \\
\hline & \multirow[b]{2}{*}{ Mean } & \multirow[b]{2}{*}{ Variance } & \multicolumn{2}{|c|}{ Maximum } & \multicolumn{2}{|c|}{ Minimum } & \multirow[b]{2}{*}{ Skewness } & \multirow[b]{2}{*}{ Mean } & \multirow[b]{2}{*}{ Variance } & \multicolumn{2}{|c|}{ Maximum } & \multicolumn{2}{|c|}{ Minimum } \\
\hline & & & Level & Date & Level & Date & & & & Growth & Date & Growth & Date \\
\hline Illinois & $5,711.0$ & $75,994.0$ & $6,059.8$ & Jun. 2000 & $5,201.4$ & Mar. 1992 & -0.64 & 0.8 & 6.8 & 11.7 & Sep. 1995 & -6.8 & Jul. 2001 \\
\hline Indiana & $2,824.3$ & $26,891.1$ & $3,015.2$ & May 2000 & $2,492.5$ & Mar. 1991 & -0.85 & 1.0 & 12.0 & 10.6 & Feb. 1999 & -10.4 & Jan. 1999 \\
\hline Kentucky & $1,705.5$ & $17,009.6$ & $1,859.8$ & Nov. 2007 & $1,461.7$ & Apr. 1990 & -0.64 & 1.4 & 16.4 & 29.6 & May 1992 & -20.1 & Apr. 1992 \\
\hline Mississippi & $1,085.0$ & $5,442.7$ & $1,171.2$ & Dec. 2007 & 928.8 & Jan. 1990 & -1.02 & 1.4 & 15.9 & 15.9 & Oct. 1993 & -18.6 & Sep. 2005 \\
\hline Missouri & $2,603.0$ & $26,105.7$ & $2,805.4$ & May 2007 & $2,294.9$ & Apr. 1991 & -0.66 & 1.0 & 10.6 & 11.0 & Apr. 1993 & -14.6 & Jan. 1991 \\
\hline Tennessee & $2,560.9$ & $39,700.8$ & $2,816.8$ & Dec. 2007 & $2,171.0$ & Apr. 1991 & -0.74 & 1.5 & 12.8 & 17.1 & Nov. 1994 & -13.2 & Apr. 1996 \\
\hline
\end{tabular}


Table 2

MSA-Level Summary Statistics

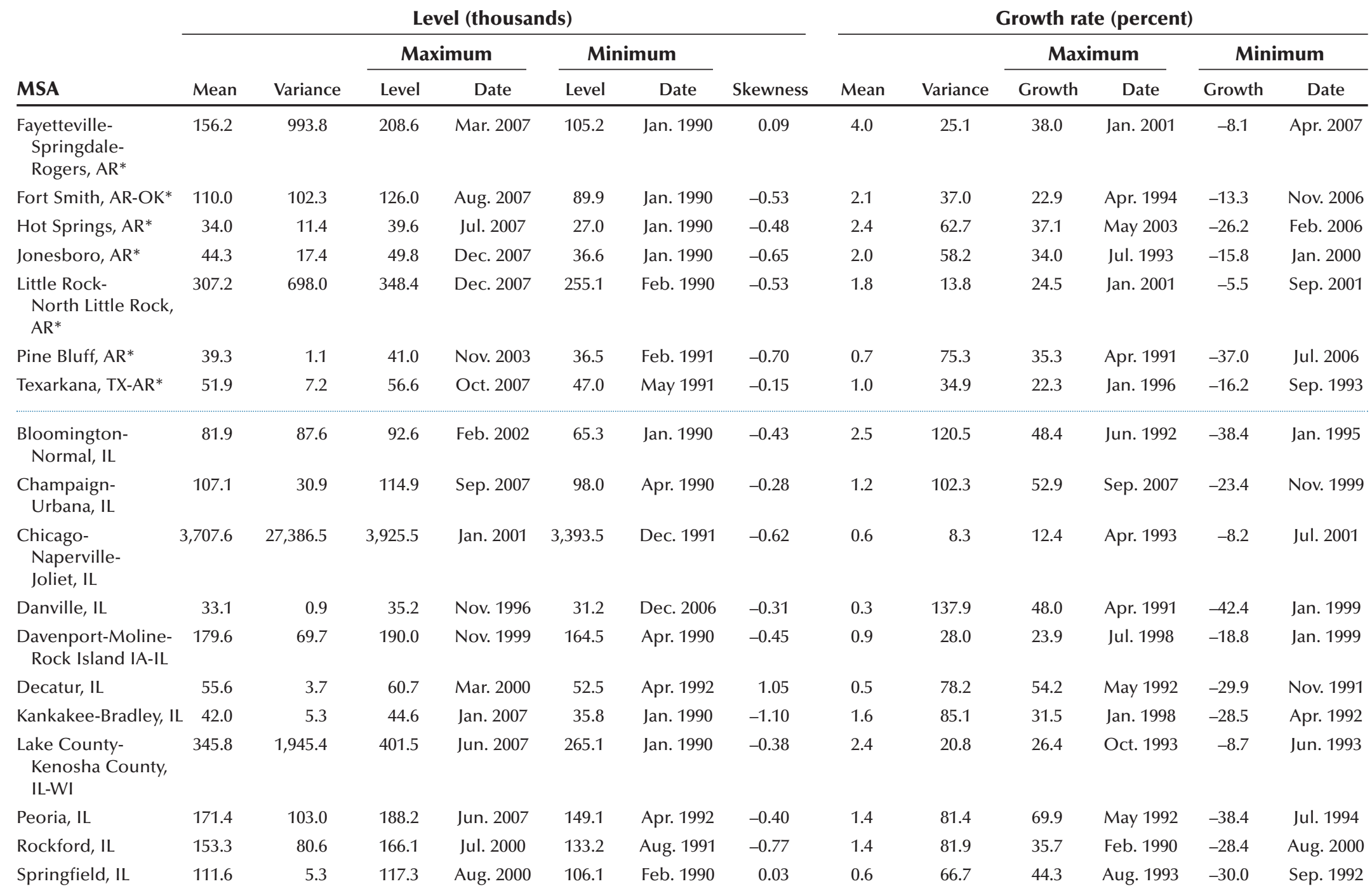

NOTE: *Indicates an MSA located in the Eighth District and used in the second experiment; monthly growth rates are annualized. 


\section{Table 2, cont'd}

\section{MSA-Level Summary Statistics}

\begin{tabular}{|c|c|c|c|c|c|c|c|c|c|c|c|c|c|}
\hline \multirow[b]{3}{*}{ MSA } & \multicolumn{7}{|c|}{ Level (thousands) } & \multicolumn{6}{|c|}{ Growth rate (percent) } \\
\hline & \multirow[b]{2}{*}{ Mean } & \multirow[b]{2}{*}{ Variance } & \multicolumn{2}{|c|}{ Maximum } & \multicolumn{2}{|c|}{ Minimum } & \multirow[b]{2}{*}{ Skewness } & \multirow[b]{2}{*}{ Mean } & \multirow[b]{2}{*}{ Variance } & \multicolumn{2}{|c|}{ Maximum } & \multicolumn{2}{|c|}{ Minimum } \\
\hline & & & Level & Date & Level & Date & & & & Growth & Date & Growth & Date \\
\hline Bloomington, IN & 75.7 & 38.5 & 85.2 & Aug. 2006 & 62.3 & Jul. 1990 & -0.80 & 2.4 & 202.9 & 80.4 & Jan. 1993 & -39.9 & Jan. 2003 \\
\hline Columbus, IN & 41.5 & 9.7 & 46.0 & Oct. 2007 & 34.2 & Feb. 1990 & -0.88 & 2.0 & 85.2 & 47.0 & Aug. 1992 & -32.3 & Jul. 1992 \\
\hline Elkhart-Goshen, IN & 117.9 & 104.8 & 133.7 & Feb. 2006 & 95.1 & Mar. 1991 & -0.58 & 1.6 & 52.8 & 22.9 & Apr. 1992 & -20.9 & Apr. 1995 \\
\hline Fort Wayne, IN & 208.5 & 80.2 & 220.0 & Dec. 1998 & 190.6 & Mar. 1991 & -0.74 & 0.7 & 27.3 & 21.5 & Jul. 2005 & -17.6 & Jan. 1999 \\
\hline Gary, IN & 273.5 & 66.0 & 285.6 & Jun. 1998 & 257.9 & Apr. 1990 & -0.34 & 0.5 & 23.2 & 21.6 & Jan. 2001 & -17.5 & Sep. 2007 \\
\hline Indianapolis, IN & 802.3 & $6,428.6$ & 921.8 & Aug. 2007 & 666.4 & Apr. 1990 & -0.32 & 1.9 & 15.7 & 18.4 & Oct. 1998 & -13.1 & Jan. 1999 \\
\hline Kokomo, IN & 50.9 & 7.5 & 55.7 & Dec. 1999 & 44.1 & Jul. 2003 & -0.01 & 2.7 & 857.6 & 312.8 & Aug. 2003 & -74.9 & Jul. 2003 \\
\hline Lafayette, IN & 87.8 & 40.3 & 97.0 & Aug. 2007 & 74.8 & May 1991 & -0.59 & 1.7 & 104.8 & 37.1 & Jan. 1995 & -51.1 & Jan. 2003 \\
\hline $\begin{array}{l}\text { Michigan City- } \\
\text { La Porte, IN }\end{array}$ & 47.5 & 1.6 & 50.3 & Apr. 2000 & 45.1 & Sep. 1991 & 0.04 & 0.4 & 36.8 & 21.8 & Sep. 1999 & -22.1 & Oct. 1997 \\
\hline $\begin{array}{l}\text { South Bend- } \\
\text { Mishawaka, IN }\end{array}$ & 140.9 & 62.7 & 150.9 & May 2000 & 123.6 & Apr. 1992 & -1.02 & 0.9 & 35.9 & 23.8 & Oct. 2004 & -20.6 & Apr. 1992 \\
\hline Terre Haute, IN & 74.4 & 6.5 & 78.2 & Mar. 2000 & 68.2 & Jul. 1990 & -0.85 & 0.6 & 43.8 & 24.5 & Jan. 1993 & -34.3 & Jan. 2003 \\
\hline Bowling Green, KY* & 51.2 & 39.8 & 62.8 & Dec. 2007 & 39.4 & Jan. 1990 & -0.15 & 3.0 & 71.1 & 46.7 & Sep. 1991 & -32.4 & Jan. 1992 \\
\hline $\begin{array}{l}\text { Cincinnati- } \\
\text { Middletown, } \\
\text { OH-KY-IN }\end{array}$ & 965.5 & $4,351.7$ & $1,047.4$ & Oct. 2007 & 859.0 & Jan. 1990 & -0.47 & 1.2 & 9.4 & 15.3 & Oct. 1993 & -6.2 & Jan. 2005 \\
\hline Elizabethtown, $\mathrm{KY}^{*}$ & 41.9 & 16.1 & 48.8 & Nov. 2007 & 35.2 & Jan. 1990 & 0.00 & 2.0 & 36.6 & 22.1 & Jan. 2006 & -15.6 & Apr. 2000 \\
\hline $\begin{array}{l}\text { Huntington- } \\
\text { Ashland, } \\
\text { WV-KY-OH }\end{array}$ & 110.0 & 35.6 & 121.2 & Sep. 2007 & 99.8 & Sep. 1991 & 0.07 & 1.1 & 34.3 & 34.0 & Feb. 1994 & -17.6 & Jan. 1994 \\
\hline $\begin{array}{l}\text { Lexington-Fayette, } \\
\text { KY }\end{array}$ & 231.3 & 407.3 & 257.1 & Dec. 2007 & 194.2 & Apr. 1990 & -0.62 & 1.7 & 22.9 & 20.5 & Jul. 2000 & -11.2 & Jul. 1995 \\
\hline Louisville, KY-IN* & 579.1 & $1,495.5$ & 629.4 & Jul. 2007 & 504.2 & Apr. 1991 & -0.70 & 1.3 & 17.3 & 16.2 & Dec. 2006 & -17.4 & Jan. 1991 \\
\hline Owensboro, $\mathrm{KY}^{*}$ & 47.8 & 12.0 & 51.6 & Dec. 2007 & 40.8 & Jul. 1991 & -0.92 & 1.5 & 38.6 & 24.5 & Apr. 1999 & -16.3 & Feb. 2003 \\
\hline
\end{tabular}

NOTE: *Indicates an MSA located in the Eighth District and used in the second experiment; monthly growth rates are annualized. 


\section{Table 2, cont'd}

\section{MSA-Level Summary Statistics}

\begin{tabular}{|c|c|c|c|c|c|c|c|c|c|c|c|c|c|}
\hline \multirow[b]{3}{*}{ MSA } & \multicolumn{7}{|c|}{ Level (thousands) } & \multicolumn{6}{|c|}{ Growth rate (percent) } \\
\hline & \multirow[b]{2}{*}{ Mean } & \multirow[b]{2}{*}{ Variance } & \multicolumn{2}{|c|}{ Maximum } & \multicolumn{2}{|c|}{ Minimum } & \multirow[b]{2}{*}{ Skewness } & \multirow[b]{2}{*}{ Mean } & \multirow[b]{2}{*}{ Variance } & \multicolumn{2}{|c|}{ Maximum } & \multicolumn{2}{|c|}{ Minimum } \\
\hline & & & Level & Date & Level & Date & & & & Growth & Date & Growth & Date \\
\hline Hattiesburg, MS & 51.7 & 26.4 & 62.1 & Aug. 2007 & 43.7 & May 1991 & -0.01 & 2.0 & 35.9 & 52.5 & Oct. 2005 & -10.5 & Sep. 2005 \\
\hline Jackson, MS & 232.9 & 471.5 & 263.4 & Oct. 2007 & 194.6 & Jan. 1990 & -0.40 & 1.7 & 10.6 & 18.0 & Jul. 2003 & -7.3 & Aug. 1990 \\
\hline Pascagoula, MS & 54.2 & 9.2 & 60.8 & Jul. 1999 & 46.1 & Jan. 1990 & -0.03 & 2.9 & 392.5 & 191.7 & Apr. 2007 & -71.6 & Sep. 2005 \\
\hline Columbia, $\mathrm{MO}^{*}$ & 77.9 & 99.2 & 93.3 & Oct. 2007 & 61.2 & Jun. 1990 & -0.24 & 2.5 & 26.9 & 22.7 & Oct. 1993 & -13.2 & Apr. 1990 \\
\hline Jefferson City, MO* & 72.2 & 44.2 & 80.3 & Dec. 2007 & 59.0 & Apr. 1990 & -0.72 & 1.9 & 32.0 & 22.1 & Jul. 1994 & -16.3 & Apr. 1995 \\
\hline Joplin, MO & 71.7 & 35.2 & 80.1 & Dec. 2007 & 60.2 & Feb. 1991 & -0.70 & 1.7 & 27.7 & 20.0 & Jul. 2004 & -14.7 & May 2002 \\
\hline Kansas City, MO-KS & 932.0 & $3,513.1$ & $1,024.2$ & Aug. 2007 & 824.1 & Jun. 1991 & -0.60 & 1.2 & 12.3 & 14.0 & Jul. 2007 & -14.8 & Jul. 2002 \\
\hline St. Joseph, MO-KS & 49.4 & 20.7 & 59.6 & Aug. 2007 & 42.8 & Jul. 1991 & 0.50 & 1.9 & 59.6 & 35.2 & Oct. 1991 & -19.8 & Sep. 1996 \\
\hline St. Louis, MO-IL* 1 , & $1,280.5$ & $4,295.7$ & $1,362.6$ & May 2007 & $1,165.0$ & Jun. 1991 & -0.58 & 0.8 & 8.1 & 10.0 & Jan. 1998 & -7.5 & Dec. 2000 \\
\hline Springfield, $\mathrm{MO}^{*}$ & 167.5 & 425.1 & 202.9 & Dec. 2007 & 131.2 & Jul. 1990 & -0.31 & 2.5 & 17.0 & 16.8 & Aug. 1990 & -11.2 & Jan. 2003 \\
\hline Clarksville, TN-KY & 70.8 & 100.4 & 85.7 & Oct. 2007 & 53.4 & Dec. 1990 & -0.26 & 2.7 & 45.4 & 25.7 & Sep. 1993 & -18.8 & Jul. 1990 \\
\hline Cleveland, TN & 38.7 & 10.5 & 42.9 & Jan. 2007 & 32.2 & Aug. 1991 & -0.74 & 2.1 & 169.0 & 109.3 & Jan. 1994 & -42.9 & Mar. 1993 \\
\hline Jackson, TN* & 55.8 & 30.5 & 62.3 & Jun. 2007 & 45.7 & Jan. 1991 & -0.59 & 1.9 & 57.8 & 31.6 & Jul. 1999 & -28.4 & Aug. 1999 \\
\hline Johnson City, TN & 73.2 & 22.7 & 81.7 & Nov. 2007 & 64.2 & Feb. 1990 & -0.10 & 1.6 & 52.7 & 31.7 & Sep. 2003 & -28.0 & Jul. 1997 \\
\hline $\begin{array}{c}\text { Kingsport-Bristol- } \\
\text { Bristol, TN-VA }\end{array}$ & 119.1 & 21.5 & 125.7 & Apr. 1997 & 107.4 & Jan. 1990 & -1.11 & 1.0 & 52.2 & 25.1 & Jul. 1990 & -24.0 & Sep. 1990 \\
\hline Knoxville, TN & 293.9 & 777.1 & 338.9 & Sep. 2007 & 240.8 & Apr. 1990 & -0.23 & 2.0 & 18.2 & 14.4 & Apr. 1993 & -11.9 & Jan. 2003 \\
\hline $\begin{array}{l}\text { Memphis, } \\
\text { TN-AR-MS* }\end{array}$ & 581.0 & $2,773.8$ & 647.1 & Dec. 2007 & 487.5 & Mar. 1991 & -0.66 & 1.6 & 22.9 & 23.4 & Jan. 1994 & -12.2 & Aug. 1993 \\
\hline Morristown, TN & 46.9 & 18.1 & 51.9 & May 2006 & 38.1 & Jan. 1990 & -0.75 & 2.1 & 87.2 & 46.4 & Jul. 1993 & -22.5 & Oct. 2002 \\
\hline $\begin{array}{l}\text { Nashville-Davidson- } \\
\text { Murfreesboro, TN }\end{array}$ & 651.1 & $5,679.1$ & 765.6 & Dec. 2007 & 522.9 & Feb. 1991 & -0.38 & 2.2 & 18.3 & 16.9 & Nov. 1994 & -7.4 & Oct. 2001 \\
\hline
\end{tabular}

NOTE: *Indicates an MSA located in the Eighth District and used in the second experiment; monthly growth rates are annualized. 
Table 3

\section{Rural Employment, by State in 2006}

\begin{tabular}{lc} 
State & $\begin{array}{c}\text { Rural employment } \\
\text { (percent) }\end{array}$ \\
\hline Arkansas & 36.3 \\
Illinois & 11.6 \\
Indiana & 20.0 \\
Kentucky & 36.0 \\
Mississippi & 52.5 \\
Missouri & 23.9 \\
Tennessee & 22.1 \\
Average & 28.9
\end{tabular}

SOURCE: USDA, Economic Research Service, State Fact Sheets.

cast. With each new period, recent data are added and data at the beginning of the sample are dropped. The rolling window scheme is particularly useful for cases in which the data-generating process experiences structural breaks. This has been shown to be the case for both state- and MSAlevel employment (see Owyang, Piger, and Wall, 2005, 2008, and Owyang et al., 2008). Therefore, we choose to use a rolling window forecasting scheme with a 13-year sampling period. The number of lags for each model is chosen using the Bayesian information criterion (BIC) on the initial subsample and remains fixed for the entire forecasting experiment.

\section{Spatial Weighting}

Two sets of weights are considered for the first forecasting experiment. The first set of weights takes into account the distance between the centroids of economic regions, and the second considers geographic contiguity as a categorical qualification. Under the first definition,

$$
w_{n k}=\left(1 / d_{n k}\right) /\left(\sum_{k \neq n} 1 / d_{n k}\right),
$$

where $d_{n k}$ is the distance between the geographic centroids of regions $n$ and $k$. Under the second definition,

$$
w_{n k}=\left(\eta_{n k}\right) /\left(\sum_{k \neq n} \eta_{n k}\right),
$$

where $\eta_{n k}=1$ if regions $n$ and $k$ are geographically adjacent, and $\eta_{n k}=0$ otherwise. Both of the final two experiments use only the distance between centroids because contiguity cannot be established for most MSAs.

\section{RESULTS}

A few broadly consistent features are notable for the three forecasting experiments. In particular, for the District forecasts the aggregate AR exhibits greater MSPEs at every horizon than the ST-AR model. The difference in MSPEs for the ST-AR model and a more parsimoniously parameterized VAR is often small, especially for short horizons; and the disaggregate AR can provide some (small) forecasting advantages over the more heavily parameterized ST-AR model at short horizons but is inferior at long horizons.

\section{Forecasting District Employment with State-Level Data}

The first set of results considers forecasting Eighth Federal Reserve District employment using state-level data. As mentioned previously, statelevel data support two possible spatial weighting matrices for the ST-AR model: distance and contiguity. We present results for both weighting matrices.

Figure 3 shows the relative decline in MSPEs for the ST-AR model using centroid distance as the spatial metric relative to each of the forecasting models. Obvious from these results is that weighting state-level interactions by distance provides some advantage to aggregate forecasting over weighting by contiguity. The advantage may result because a contiguity weighting scheme would suppress potentially important interactions between noncontinuous states. ${ }^{10}$

For both weighting schemes, the informational advantage in modeling the regional interactions

\footnotetext{
10. As alluded to above, the weighting matrix in spatial econometrics is determined exogenously. Conley and Molinari (2007) propose a test of the spatial weighting matrix. However, their test is conducted in-sample and is a joint test of model and spatial weighting misspecification.
} 


\section{Figure 3}

\section{Efficiency Gain for ST-AR Model, Using Eighth District States}

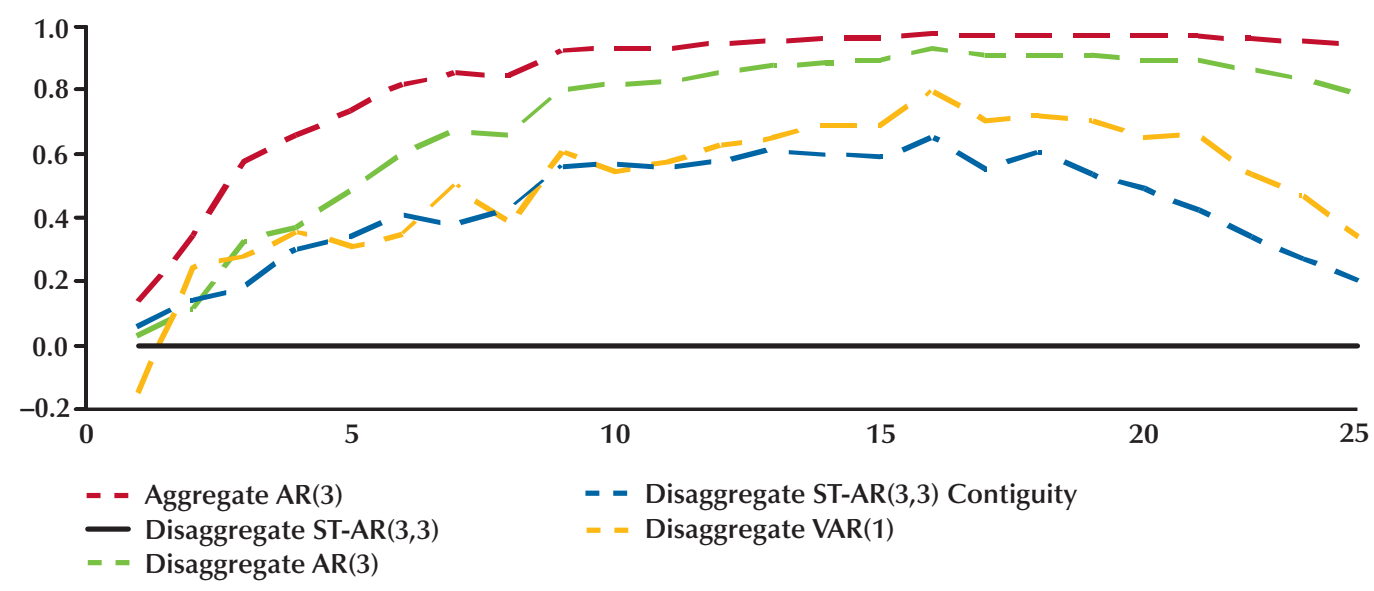

\section{Figure 4}

Efficiency Gain for ST-AR Model, Using Eighth District States (setting equal lag lengths)

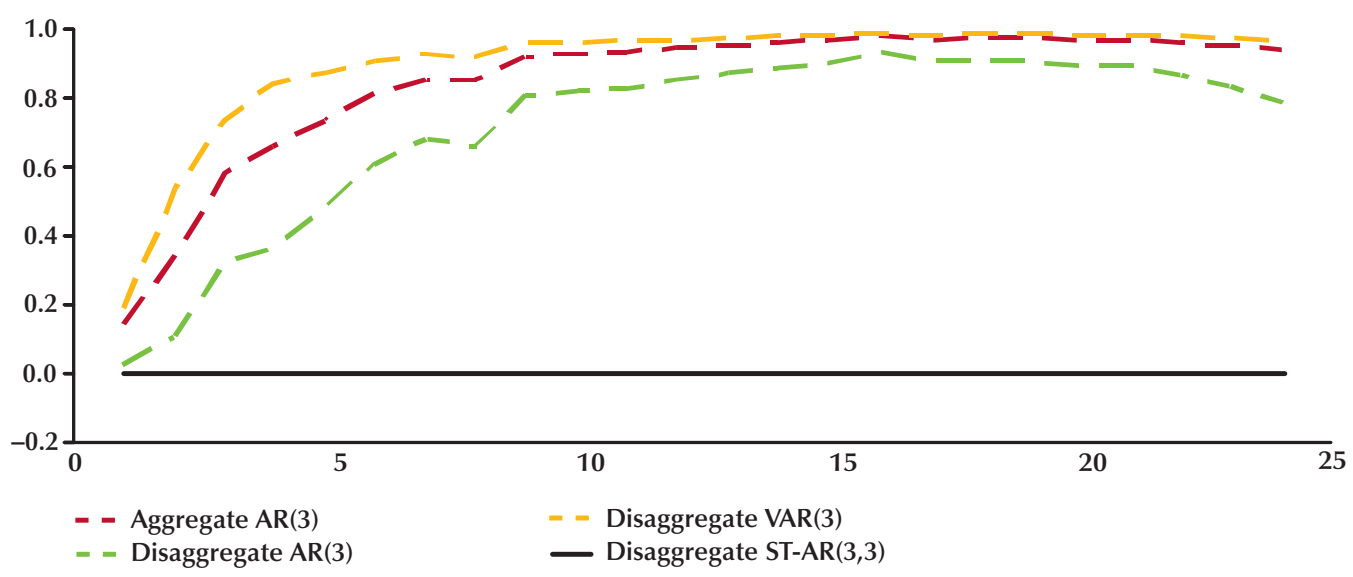




\section{Figure 5}

\section{Efficiency Gain for ST-AR Model, Using Eighth District MSAs}

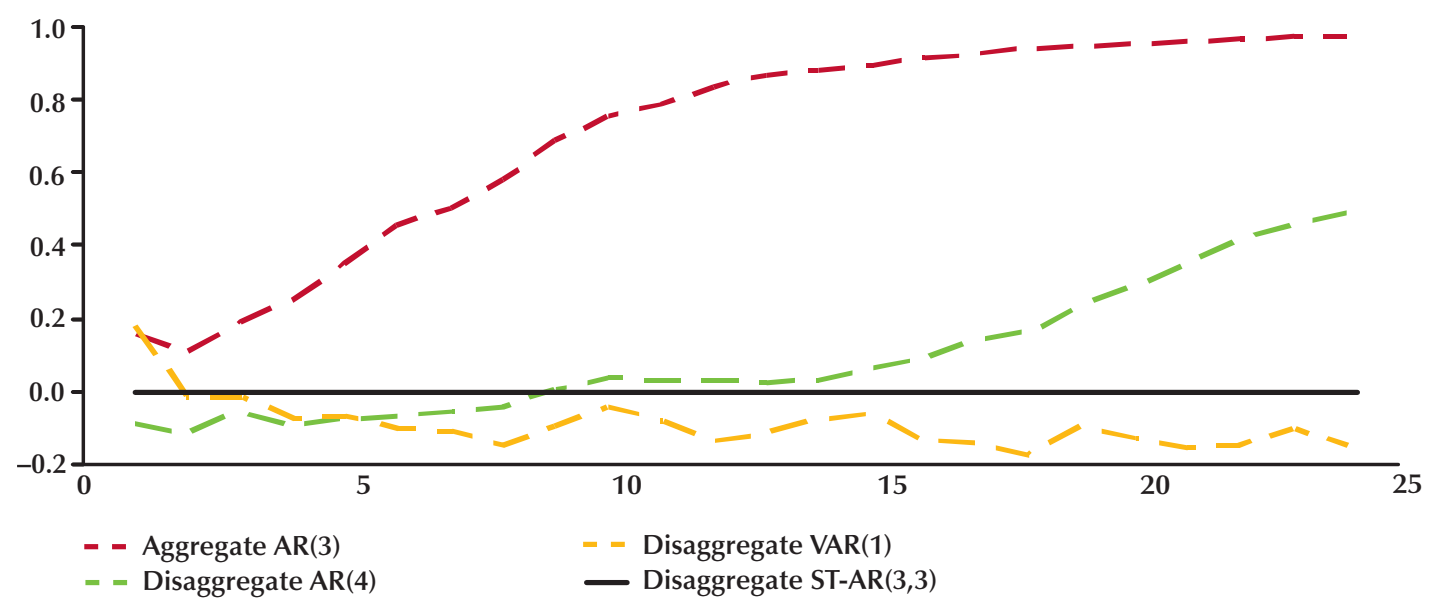

is obvious. The VAR and the ST-AR models yield lower MSPEs for almost every horizon. At very short horizons, the disaggregate AR has predictive ability similar to that of the VAR and the ST-AR models. However, at longer horizons, neglecting the regional interactions can increase the MSPE by up to 90 percent.

The regional VAR and the ST-AR models produce an interesting comparison. First, it is important to note that the lag order chosen by the BIC for the VAR is much shorter than that for the ST-AR. This negates, to some extent, the reduction in the MSPEs gained by reducing parameter uncertainty in the more parsimoniously parameterized ST-AR model. Figure 4 demonstrates the informational advantage for a ST-AR model versus a VAR with equal lag length. This finding is consistent with the theoretical findings in Giacomini and Granger (2004): Increasing the number of estimated parameters in the VAR with equal lags leads to potential overfitting and an increase in the MSPEs.

\section{Forecasting District Employment with MSA-Level Data}

As Figure 5 shows, the results for disaggregating at the MSA level are broadly consistent with those for the state data. The disaggregate models perform better out of sample than the aggregate AR model. The ST-AR model is more efficient than the disaggregate AR at long horizons. At shorter horizons, this information advantage is eroded and sometimes negative. Moreover, the VAR performs better in this case than the ST-AR model for most horizons.

These results suggest several possible explanations. In the previous case, District data were disaggregated into seven states; here, the District is disaggregated into 18 MSAs. Although the increase in the number of disaggregate units may not seem significant, it leads to a substantial increase in the number of estimated parameters for the ST-AR model. This increase may erode the model's forecasting advantage because of the increased uncertainty from estimating the extra parameters. Second, the MSA may be an improper level of disaggregation. A third possibility is that the spatial weighting matrix used in this exercise does not properly model the interactions. This could potentially explain why the VAR model performs better than the ST-AR model despite estimating a comparable number of parameters. 


\section{Figure 6}

\section{Efficiency Gain for ST-AR Model, Forecasting State Employment with MSAs}
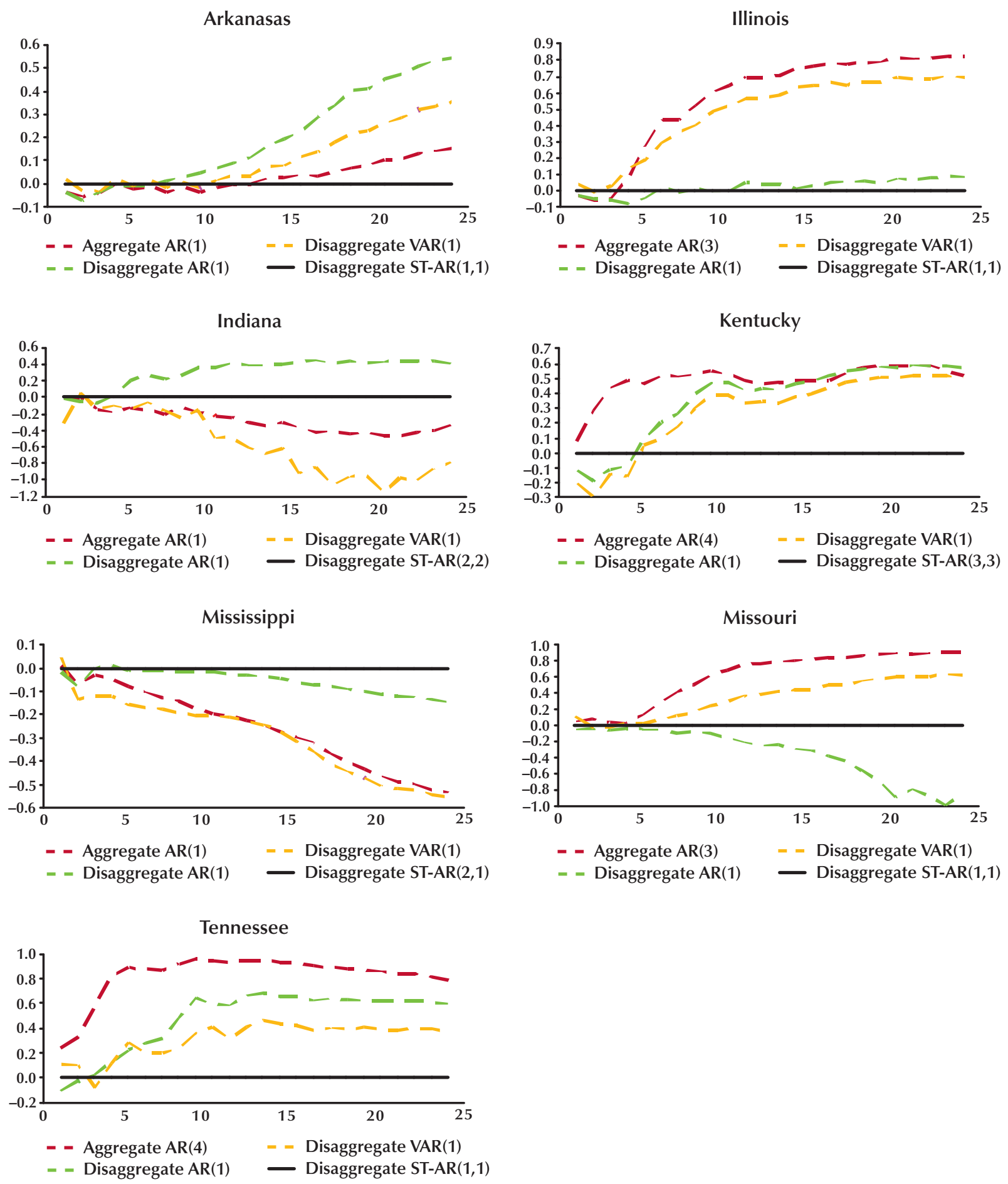


\section{Forecasting State Employment with MSA-Level Data}

We conducted similar experiments using the level of employment in the seven states in the Eighth District as the aggregate and the MSAs in those states as the disaggregate components. Our motivation is to determine the optimal level of disaggregation in forecasting employment. Unfortunately, few results are consistent across states (Figure 6). For example, most states yield lower MSPEs for the disaggregate forecasting models versus the aggregate AR model. Mississippi is an exception: The aggregate AR gives roughly similar MSPEs as the VAR and much lower MSPEs than either the ST-AR or disaggregate AR model. Overall, the model with the lowest MSPE for each state differs. The ST-AR model provides the lowest MSPE for about half of the states but performs considerably worse than even the aggregate AR for Mississippi and Indiana.

One notable fact in these results is that, for a given model, the lag order called for by the (insample) BIC varies substantially across the states. Not surprisingly, the ST-AR model tends to perform worse in states in which the in-sample criterion calls for longer lags. This can lead to an increase in parameter uncertainty or overfitting. ${ }^{11}$ Similarly, for states in which long lags are called for in the AR model, this model performs poorly.

\footnotetext{
11 The tension between in-sample and out-of-sample fit is not surprising (see Hansen, 2008).
}

We therefore conclude that, although some information may be gleaned from modeling spatial relationships, disaggregation to the MSA level should be done with some caution.

\section{CONCLUSION}

Recent studies have shown that, at times, aggregate variables can be more accurately forecasted by summing disaggregate forecasts. In particular, using models that take into account the spatial interactions of the disaggregate series can improve forecasting performance. This occurs at the expense of estimating additional parameters. This tension naturally leads to the question of how much disaggregation is "optimal."

We conducted a number of forecasting experiments along these lines. In general, we find that disaggregation can produce better forecasts. For example, by disaggregating a regional variable (the Eighth Federal Reserve District's employment level) into states, we achieved a significant reduction in the MSPE versus the aggregate AR. Using the state level as the aggregate, however, yields less consistent results, which suggests that the exploitable regional interactions at the MSA level may not be sufficiently informative to overcome the increase in estimated parameters. We imagine that further disaggregation-perhaps to the county level-might increase this tension between exploitable spatial interactions and increased parameter uncertainty. 


\section{REFERENCES}

Baird, Catherine A. “A Multiregional Econometric Model of Ohio.” Journal of Regional Science, November 1983, 23(4), pp. 501-15.

Ballard, Kenneth and Glickman, Norman J. "A Multiregional Econometric Forecasting System: A Model for the Delaware Valley.” Journal of Regional Science, August 1977, 17(2), pp. 161-77.

Conley, Timothy G. and Molinari, Francesca. "Spatial Correlation Robust Inference with Errors in Location or Distance.” Journal of Econometrics, September 2007, 140(1), pp. 76-96.

Crow, Robert T. “A Nationally-Linked Regional Econometric Model.” Journal of Regional Science, August 1973, 13(2), pp. 187-204.

Duobinis, Stanley F. “An Econometric Model of the Chicago Standard Metropolitan Statistical Area.” Journal of Regional Science, August 1981, 21(3), pp. 293-319.

Giacomini, Raffaella and Granger, Clive W.J. "Aggregation of Space-Time Processes.” Journal of Econometrics, January 2004, 118(1/2), pp. 7-26.

Glickman, Norman J. “An Econometric Forecasting Model for the Philadelphia Region.” Journal of Regional Science, April 1971, 11(1), pp. 15-32.

Hansen, Peter R. "In-Sample Out-of-Sample Fit: Their Joint Distribution and Its Implications for Model Selection." Unpublished manuscript, 2008.

Hendry, David F. and Hubrich, Kirstin. "Forecasting Economic Aggregates by Disaggregates.” Working Paper No. 589, European Central Bank, February 2006; www.ecb.eu/pub/pdf/scpwps/ecbwp589.pdf.

Hernández-Murillo, Rubén and Owyang, Michael T. "The Information Content of Regional Employment Data for Forecasting Aggregate Conditions.” Economics Letters, March 2006, 90(3), pp. 335-39.

LeSage, James P. and Magura, Michael. "Econometric Modeling of Interregional Labor Market Linkages.” Journal of Regional Science, August 1986, 26(3), pp. 567-77.

LeSage, James P. and Magura, Michael. "Using Bayesian Techniques for Data Pooling in Regional Payroll Forecasting." Journal of Business and Economic Statistics, January 1990, 8(1), pp. 127-35.

Liu, Yih-wu and Stocks, Anthony H. "A Labor-Oriented Quarterly Econometric Forecasting Model of the Youngstown-Warren SMSA.” Regional Science and Urban Economics, August 1983, 13(3), pp. 317-40.

Owyang, Michael T.; Piger, Jeremy and Wall, Howard J. "Business Cycle Phases in U.S. States.” Review of Economics and Statistics, November 2005, 87(4), pp. 604-16.

Owyang, Michael T.; Piger, Jeremy and Wall, Howard J. "A State-Level Analysis of the Great Moderation." Regional Science and Urban Economics, November 2008, 38(6), pp. 578-89.

Owyang, Michael T.; Piger, Jeremy M.; Wall, Howard J. and Wheeler, Christopher H. "The Economic Performance of Cities: A Markov-Switching Approach.” Journal of Urban Economics, November 2008, 64(3), pp. 538-50. 


\section{Engemann, Hernández-Murillo, Owyang}

Rapach, David E. and Strauss, Jack K. "Forecasting Employment Growth in Missouri with Many Potentially Relevant Predictors: An Analysis of Forecast Combining Methods." Federal Reserve Bank of St. Louis Regional Economic Development, 2005, 1(1), pp. 97-112; research.stlouisfed.org/publications/red/2005/01/RapachStrauss.pdf.

Rapach, David E. and Strauss, Jack K. "Forecasting Real Housing Price Growth in the Eighth District States." Federal Reserve Bank of St. Louis Regional Economic Development, November 2007, 3(2), pp. 33-42; research.stlouisfed.org/publications/red/2007/02/ Rapach.pdf. 